\title{
Exploring the Relevance of Appropriate Training in Digital Education for Women's Employment in Saudi Arabia
}

\author{
Nailah Hassan Gadi ${ }^{1,2}$ \\ ${ }^{1}$ Hull University, Hull, UK \\ ${ }^{2}$ Taif University, Taif, Saudi Arabia \\ Email: nailahalgadi@yahoo.com
}

How to cite this paper: Gadi, N. H. (2021). Exploring the Relevance of Appropriate Training in Digital Education for Women's Employment in Saudi Arabia. Open Journal of Business and Management, 9, 2988-3010. https://doi.org/10.4236/ojbm.2021.96167

Received: October 7, 2021

Accepted: November 21, 2021

Published: November 24, 2021

Copyright $\odot 2021$ by author(s) and Scientific Research Publishing Inc. This work is licensed under the Creative Commons Attribution International License (CC BY 4.0).

http://creativecommons.org/licenses/by/4.0/ (c) (i) Open Access

\begin{abstract}
This research explores the need for an appropriate training in digital technology on women's employment in the Kingdom of Saudi Arabia. This research area is currently of great value and interest because of the dramatic technology-driven changes that are taking place worldwide. This is particularly the case in Saudi Arabia, where technology is being promoted by the Saudi government as cornerstone of economic development. This study has adopted a methodology based on the structuration theory to explore the complexity involved in the subject matter which warranted the selection of participants from three key social structures: government, businesses and academic institutions and the results of semi-structured interviews with 40 participants guided the researcher to derive important findings presented in this study. The study found that the aura of cooperation between academic institutions and businesses exists in Saudi Arabia for training and up-skilling female students and women employees. The results showed that universities are willing to provide library services and allocation of slots on different courses dedicated for female employees in industries, while the stakeholders from different industries in this study showed prospects for accepting female students in the internships programs allowing them to complete their final year projects in digital technologies. These arrangements raise the potential of equipping women with digital skills and training, so that they can participate in the labour-market created by the digital technologies. The study also found that academic institutions have in place good arrangements for providing training in vocational fields such as applied science, pharmacology, public health sector and IT. The study recommends that the participation rate of women to take up the vocational education and training opportunities should be increased through incentive program by Saudi government for women and ar-
\end{abstract}


rangement of employers arranged workshops aiming to raise the awareness among women about the need of vocational education and training in digital technologies.

\section{Keywords}

Digital Technology, Women's Employment, Vocational Training, Digital Competencies, IT, Education, Careers, Skills: Saudi Arabia

\section{Introduction}

The digitalization of Saudi society is planned in response to the rapid-drop in the oil prices globally, which is an attempt to shift the dependence of the country from oil exporting to the one innovator and implementer of the digital technologies for driving the economic growth (Youssef et al., 2020). There are some other factors which led Saudi Arabia to adopt and implement the digital transformation for achieving the economic growth. Firstly, the Saudi Arabia opened up its borders for the foreign investors, which resulted in the growth of firms and multinational companies with the promise to hire the Saudi nationals for development of national workforce (Sabbagh et al., 2012; Amuda, 2020).

Secondly, almost half of Saudi population is under 25 years old, which suggests that young and enthusiastic workforce is available to fulfil the workforce needs of the firms using and investing in the digital transformation of the country. With growth of private sector, it is expected that more than $80 \%$ of the Saudi population will be employed with a net increase in the per capita income (Woishi, 2019).

According to survey report issued by Reddy and Minoiu (2009), the per capita income is decreased for more than 50 out of 100 households in the Saudi Arabia between 1960-2001, which has increased the economic pressures on families and the government alike to seek some alternative solutions to fund the families' budgets. The digitalization of Saudi economy brings some ray of hope for the families to improve their economic status through allowing women to develop careers in digital technologies if the opportunities are actually generated by digital technologies in Saudi labour market (Al-Helayyil et al., 2016).

Furthermore, due to lifting bans and restrictions on movement and education of women in the local and foreign universities, the skilful workforce in different areas can be derived from the Saudi females who are aspiring to achieve their economic growth. As recorded in 2018, Saudi population consists of 10.2 million females, which is almost equal to Saudi men (10.6 million), which can directly contribute towards the economic growth of country as a result of digital transformation thorough setting their businesses or can pursue careers in firms using and developing the information and communication tools (Al-Helayyil et al., 2016; Statista, 2018). This can add to the employment opportunities for women 
aspiring to start careers in the digital technologies. Currently, there is no evidence as to which extent the digital transformation has opened up opportunities for Saudi women, as argued by Al-Helayyil et al. (2016), which warrants further research to look into this issue. Has the digitalization of economy as envisioned by government increased the employment opportunities for women? This question is yet to be answered by the empirical evidence. With growth of digitalization in public and private sector, I hypothesize that digitalization has impacted women pursuing careering in digital technologies in terms of increasing employment opportunities for them.

There are five main sectors which are being digitalized as part of the Vision 2030 in order to digitalize the Saudi economy the public institutions providing social services to the communities in Saudi Arabia. The government has dedicated 1.6 billion US dollars to develop the digital infrastructure for facilitating the e-government services to the residents in Saudi Arabia. The development and application of e-government services ranging from payment of utility bills to the recruitment of employees via the e-platforms and assessment tools are more likely to improve the employment opportunities for both male and females (Vision2030.gov.sa; Alharbi, 2019). It will be interesting to understand the landscape of the employment opportunities for females aspiring to pursue careers in digital technologies, especially from the viewpoints of participants from the governmental agencies responsible for managing the employment opportunities for Saudi citizen.

Regardless of country's development, education and training are key indicators for preparedness for women to exploit the job opportunities created by digital technologies. The women's participation in the developed world can be partially attributed to the equal opportunities for women in the education systems in the USA and other developed countries, however, several scholars argue that disparities in the male and female in the job market are still found even in developed countries, and participation of females in the job is not at par with the that of men, which might be indicative of some flaws and weaknesses either in the training and education for women, thereby leading to lapses in delivery of digital competencies which are demanded by the employers.

The level of digital literacy especially for women in Saudi Arabia is very low. This stems from the fact that digital literacy is an understudied field of study in Saudi Arabia, especially as it relates to women. The Saudi government's desire to diversify its economy away from oil revenue and toward information technology has never been more pressing. It's worth noting that, in order to increase job opportunities, digital skills are necessary. Women require digital competences at all levels in order to improve their work prospects, which are heavily reliant on the quality of training programs. Hence, the need for a robust the training in digital education for women's employment in Saudi Arabia. This study serves as a model for how the government may encourage women to learn information technology skills in order to improve their employability. This is in fact one of 
the novelties of this paper.

The paper is organized by introducing some salient features which clearly indicate the need for this research followed by literature review where the research gaps are pin-pointed. The methodology of the paper was described and then later results were presented and have been thoroughly discussed.

\section{Literature Review}

Putting aside for the moment national government initiatives to encourage women's participation in the new technological work-place, the paper first emphasises in this section how vital it is to consider research which has cast the spotlight on school-level education on an international level as evidence that the outlook for women is not encouraging in the technology domain. The review emphasizes on three basic areas; these are the levels of digital competencies, skill adoption and creation and adaptation of digital technology.

\subsection{Levels of Digital Competencies for Women's Employments}

According to a report, around $85 \%$ - $90 \%$ of the potential workforce will be required to possess the ICT skills in order to perform the key functions in organizations, thereby suggesting the development of digital skills and competencies is an important aspect of the policies and programs aimed at increasing the employment opportunities for women (Economic and Social Council of United Nations, 2018). According to report of Broadband Commission (2017) for Sustainable Development, the major cause of low employability of women is poor digital competencies such adaptation and creation of digital technologies to suit to business needs, which results in employers giving preferences to men for fulfilling the ICT-related roles in businesses in OECD countries. The recommendations suggested that initiative aiming to put the women at work must target the provision of necessary digital skills. Broadband Commission for Sustainable Development is an international agency sponsored by UNESCO (United Nations Educational and Scientific and Cultural Organization) and ITU (International Telecommunication Union), and aims to promote digital skills among users of digital technologies (Broadband Commission, 2017).

Some other researchers commented on the relationship between digital skills and employment opportunities for women in the labour market. Van Dijk and Van Deursen (2014) argue that digital competencies are not only essential for doing things within organizations, but they are also vital for creating sustainability within the social and civic domains of life.

The employers may require digital competencies of different levels on behalf of women in order to consider them fit for performing the organizational functions (Pande \& Weide, 2012). Therefore, Eshet-Alkalai (2004) places emphasis on the diversity of skills including the technical, social, cognitive skills in order to work with the digital technologies at workplaces and homes as well, indicating the complexity of the digital skills and competencies which is beyond the digital 
literacy. The digital literacy involves using the ICT tools for searching information, retrieving the required material, and ability to use the digital tools for communication with others. The concept of digital competencies has become multifaceted, and will keep evolving with the inventions of new ICTs tools and applications (Ferrari, 2013).

World Economic Forum (2016) has reported the possession of the cognitive/ physical abilities, basic skills involving the content processing competency, social systems and digital technology-aided problem-solving skills are harnessing the future job opportunities for women in the tech-dependent SMEs. OECD (2016) reported that girls cannot harness the potential job opportunities in the global labour market, unless if they have competency in understanding, using and adopting the digital technologies, and committed to the life-long learning process for adapting to the changing digital landscape, and competent in digital entrepreneurship, ICT-enabled communication skills and logical thinking.

These skills of women at each level of the pyramid of ICT skills as shown in the figure 2.4 predict the availability of employment opportunities for women at different levels of their career, such as exploitation of job opportunities at basic and advanced levels will depend on the knowledge and skills possessed by women at the respective level of careers. Similarly, the promotion of existing female employees to higher level of digital career will also hinges upon the acquisition of skills by women. Hence, description of digital skills at different levels of digital careers as described in this section may help me to gain insight into the viewpoints of participants about the digital skills of Saudi women to harvest employment opportunities resulting from the digital proliferation in Saudi Arabia.

\subsection{Skills at Adoption Levels of Technologies}

The digital competencies required at the adoption of technologies level include the provision of basic education and literacy, and sufficient insight into working and utilities of technological devices and services (Gurung, 2018). The basic use of technologies level involves the women to show the basic understanding of software applications, security concerns of digital technological use, digital privacy, data storage methods and solving problems through the use of digital devices (Göransson \& Rolfstam, 2013). Furthermore, women's competencies is not a standalone factor, there are some other factors such as skills of collaboration, communication, generation of novel contents which can complement the digital skills, and collectively can play a critical role in economic empowerment of women. The adoption level of skills in terms adopting technologies to meet their own daily needs is necessary for all women for their successful participation in the labour market (Barua \& Barua, 2012).

Gurung (2018) revealed that digital literacy for all making the individuals and companies to adopt the digital technologies is a fundamental requirement for full participation in the digital society. The knowledge of the existing and emerging digital applications, privacy and security while using the digital applications 
equip the individuals with skills to extract the key and useful information from the internet sources rather than being a passive target for online advertisements (Gupta, 2015). The basic knowledge of working and functions of digital technologies are useful sources of improving efficiency of women in using the digital applications productively, especially for economic empowerment, and optimize the usage of various forms of digital devices for increasing the chances for employment in the male-dominated digital market (Leach \& Turner, 2015).

The skills discussed in this section seem to be important for women to use the digital technologies at the adoption level which can be applied to perform digital technologies-assisted tasks to earn money. For example, women use social media to chat with their friends and family members, which might be used to market products to members on social media to earn money. The acquisition of basic knowledge and skills can help stakeholders (businesses, government and academia in this study) to assess the suitability of digital career at earlier stages of digital careers to be pursued by Saudi women. Of note, women possessing digital skills at this level do not necessarily mean that they intend to pursue the digital careers resulting from digital proliferation in Saudi Arabia. Therefore, some advanced level skills are critically important for employers to consider females candidates for employment opportunities arising from the digital proliferation in Saudi structures (business, government and academia) as described by structuration theory.

\subsection{Creation and Adaptation of Digital Technology}

The levels of creating and adapting to the digital technologies are more suitable for the ICT professionals (Rashid, 2016). The women aspiring to embark upon the ICT-related careers are required to show the basic computing skills and sufficient understanding with the basic software and algorithms, codes, generation and dissemination of contents, working with teams, and promotion of logical thinking through the digital devices (Herbert, 2017). The employers will look at the afore-mentioned skills in order to evaluate women's suitability for particular positions in their organizations. The computing skills of women is interesting to be explored from participants' perspectives, as they may affect the availability of job opportunities for Saudi women arising from the digitalization of organizations in Saudi Arabia. Moreover, structuration theory also suggests that organizational leaderships (stakeholders) interact with agents (women in my research work) to assess the preparedness of agents for joining ICT careers.

After having the expert knowledge and skills in creation and adaptation of digital technologies such can enable women to successfully grab employment opportunities if they have programming knowledge, and skills (Clarke et al., 2012). The individual with skills of adapting to digital technologies can easily modify the functions of the existing digital devices and software to fit into their business needs, and is only possible if the companies and individuals had prior knowledge of the basic usage of such systems within a particular business envi- 
ronment. The individuals with basic understanding of algorithms, software and devices make use of the online sources for creating digital applications which satisfy the business requirements (Kane et al., 2015; Melhem et al., 2009).

Women in the advanced countries carry advantageous position compared to the women in developing countries to learn the skills of creating and adapting to the emerging digital tools, as they have more sophisticated infrastructure, social resources for obtaining high-level trainings for introducing and modification of the existing digital devices (Rosenthal, 2008). Similarly, in developed countries, women would have the opportunities to learn machine learning techniques and usage of the intricate algorithms which are essential for creation of new technologies (Bandura, 2002).

The perceptions of stakeholders about the digital competencies and potential employment opportunities created by digital technologies are most likely to reveal the degree of impact of digital technologies in improving the employment opportunities in tech-dependent organizations in Saudi Arabia. Therefore, it is critical to understand the roles of social institutions such as governments, business organizations, and academic institutions with regard to the enhancement of women's digital competencies.

Taken together, it can be concluded that digital competencies ranging from the adoption and basic use of digital devices and tools to the adaptation and creation of existing and new digital technologies are of utmost important for women to participate in the labour market. The interaction of structures/stakeholder organizations with women will be determined through the level of digital competencies possessed by Saudi women. Therefore, designing questions about the perceptions of stakeholders about the relationship between women skills and employment opportunities were included in this current study.

There is a lack of evidence regarding the impact of digitalization of Saudi industries and society on women's employment; and this has led the current researcher to investigate the impact of training and education in information and communication technologies on women's employment in Saudi Arabia. The study therefore assesses the training opportunities available for Saudi women for development of ICT-related knowledge and skills to strengthen their employability skills.

\section{Materials and Methods}

\subsection{Method of Data Collection}

\subsubsection{Sampling}

Purposive sampling was the strategy adopted in this study where, as Neuman (2002) indicates, "Purposive sampling occurs when a researcher wants to identify particular types of cases for in-depth investigation to gain a deeper understanding of types". The purposive sample technique is used for recruitment of samples from the relevant organizations in this study, which enabled the researcher to target the participants which met certain criteria. For instance, the 
participants who are representative of academic, government and business groups must hold decision-making positions within organizations, such as recruitment of employees, and digitalization of operations.

The study also pays a particular attention to the number of sample to be drawn from all of these groups. Selection of the appropriate number of interviewees is hence subjective. Perry (2000) suggests that 30 - 35 are required for conducting a qualitative research at the doctorate level, whereas Bauer and Gaskell (2000) suggest between 10 - 15 participants, arguing that the main concern is the quality of the information rather than the number of the respondents.

The participants in this study were comprised of forty people who were selected to reflect different experiences. The participants were divided into three main groups based on their affiliations with the respective organizations: government, academia and business whose roles and responsibilities affect women's relationship with technology (Table 1).

\subsubsection{Semi-Structured Interviews}

The semi-structured interviews were used as data collection tool, which fits well into the qualitative research approach adopted by this study. The choice and justification of semi-structured interview as a data collection tool since interview method is an appropriate data collection technique for use with an interpretive paradigm (Smith, 2007). Interviews help researchers to understand the feelings and thoughts of people expressed through speech and body language, enabling them to answer the questions in a natural way (Husse \& Hussey, 1997). In this study, semi-structured interviews were applied. Semi-structured interviews are commonly used in qualitative research (Collins \& Hussey, 2003; Saunders, 2012). The semi-structured interview subsequently uses open-ended and probing questions to allow the respondents to express their experiences in depth, while providing enough guidance and structure to ensure that the discussion remains focused on the researcher's topic of interest.

\subsubsection{Data Collection Process}

The process of data collection includes the preparation of the interviews, the pilot study, the design of the final interview protocol, field access, and then the conduct of the actual interviews.

Table 1. Participants in semi-structured interviews in Saudi Arabia.

\begin{tabular}{cccc}
\hline Stakeholder & Female & Male & Total \\
\hline Government & 6 & 4 & 10 \\
Academia & 13 & 2 & 15 \\
Business & 9 & 6 & 15 \\
Total & $28(70 \%)$ & $12(30 \%)$ & 40
\end{tabular}

Source: Field survey. 


\subsubsection{Preparation for Data Analysis}

Preparation for the data analysis requires several steps: recording, transcription, translation and validation of the recording, transcription and translation. These steps are explained taken to ensure that the accurate data analyses are performed.

\subsection{Data Analysis}

Thematic analysis was used for analysing the qualitative data obtained from the participants in this study; and is considered to be a useful tool for analysing the textual data or interview transcripts (Braun \& Clarke, 2006). Thematic analysis carries several advantages. First, it is a flexible and straightforward technique that can be modified for different qualitative studies depending on the research questions and accounts of participants which "Provides a rich and detailed, yet complex account of data" (Braun \& Clarke, 2006). Various techniques were used to analyse 4 the data. These include;

- Reading, Thinking and Annotating, Marking and Linking.

- Importing data into NVivo.

- Coding and Sorting Codes in Nodes.

- Searching for themes.

- Interpretation.

- Writing the Report.

\section{Result}

\subsection{Training in Cutting-Edge Technologies}

Indeed, the consensus amongst Saudis today is that work in the future will involve artificial intelligence, robotics and big data. Here, participants gave various responses about career choices. Most of the participants claimed that they were able to pursue a career of their choice driven by individual factors. For example, the first participant here mentioned that motivation and knowledge could affect her choice of a better career.

"I think that the motivation and knowledge are playing an important role. I think that if I graduate, I think I can be the chief executive of the company."

A respondent indicate that had her own accounting consultancy business and delivered accounting classes online using the relevant software. She was hired because of her knowledge and her ability to help others. Like the second participant with robots, the first participant had a clear picture of her future career plans.

"I feel that I can, in particular in the field of robotics."

The first participant thus wanted to pursue her interest in technology and update her knowledge and skills in the field. What is more, she wanted to be employed in the field of robotics.

Artificial intelligence and the use of robotics, tools and apps are the area of future cutting-edge career opportunities. These advanced activities underscore 
the importance of training and educational courses in technology for Saudi women, including their use in the academic sector for training purposes.

All of these three participants agree that vocational education and training are available in the health sector in different specialities, such as robotic surgery in the uterus, urinary tract and brain tumours etc. For example, Sultan/A said:

"Vocational education and training are available, such as using computers in the surgery, robotic surgery in the uterus, urinary tract and brain tumours, female technicians for operations, female technicians for equipment and medical engineering, which suffers from the weak demand."

When I visited the hospital to conduct the interview, I observed a high rate of digital technology adoption in the radiology and physiotherapy departments. The implication here is that students being trained for the health sector receive training in the use of highly advanced technology.

Finally, other participants expressed the view that education is improving with further work needed on the balance between practical and theoretical instruction. As Ahmad/A attested, the secondary school curriculum is currently being developed to train Saudi girls on how to deal with robots,

"Vocational education and training are strongly available. For example, some female teachers trained female students on high-tech Artificial Intelligence (robot) programming and applications, and then they participated in a contest in Canada to view their inventions."

Studies of training in robot programming and applications in Canada support the previous claim made by Seham/A about overseas training in Western countries (Vaganova et al., 2019). It seems that the education sector has achieved a degree of development in the robotics field and the government has launched a number of vocational training and educational programmes. While these training programmes are intended to prepare people in private or public sectors to work in their own business, trade and craft using technology, Saudi Arabia's Ministry of Labour has also created programmes to improve the training of employees.

One example is the HRDF programme in which the government sponsors specific training programmes for women, such as mobile phone maintenance and repairs. The government has also introduced some programmes, such as training abroad, practical vocational training, digital art and animation, as well as the use of advanced technical devices that help in the study of space science, earth sciences or nanotechnology.

Here, Areej/G noted that although the HRDF programme has the aim of "Saudising" the sector, and thus represents a very important initiative observed, the government is still focused on practical training in the service of producing the conditions of greater gender equality:

"Focusing on the practical rather than the theoretical side and focus on training in all disciplines and linking technology."

However, Ethar/A gave an opposite point of view about education, focusing 
on the theoretical side rather than practical applications. She noted that most undergraduate students who studied computer sciences attended extra courses in the computer institute to develop programming subjects.

"Recently government and academic institutions in consultation with employers have agreed to provide extra training in the areas where female students struggle. The example of such initiative is that the female graduates in computer science lacking in skills and competencies are given extra course by the academic institutions or vocational colleges for increasing their digital competencies, so that they can meet the requirements of the labour market."

Areej/G and Ethar/A and voiced the similar opinions about the availability of the extra training opportunities for female students in the engineering and technology disciplines. However, it is not clear from the data that to which extent these training programs are implemented across the national academic institutions for fulfilling the women's needs for digital competencies in Saudi Arabia. The participants could not reveal the scale and scope of training opportunities, which might be due to sensitivity of data and confidentiality of data-related policies within the participating governmental bodies.

In girls' secondary schools, for instance, the curriculum includes some programmes in computer sciences. Yet this seems insufficient, as students need more curricula focus and training to improve their technical skills to achieve a better career in this area. Mariam/G raised a new point about technological arts:

"Government policy for vocational training is to support technical training. For example, the Technical College for Girls helps to provide training in some skills without limitation in all areas, such as technical support of Technological Arts."

Mariam/G also gave the example of digital art. She confirmed that Saudi technical colleges encouraged training in this area to keep pace with the technological advances in animation, graphic design and 3D modelling, to take some examples.

In addition, Seham/G mentioned that the King Abdul-Aziz City for Science and Technology (KACST) has a great interest in advanced technical devices for women:

"King Abdul-Aziz City for Science and Technology provides each researcher with a training plan including training on some of the skills and advanced technical devices that help in the study of space science, astronomy or Nano technology."

This initiative represents a great opportunity for women who study science and technology in offering a stimulating mixed gender environment for undertaking research using advanced technical devices in diverse science and technology subjects supported by leading education specialists.

Many participants said that the government-sponsored education and training programs are playing an important role in nullifying the family pressures on females who are not allowed to travel without their family members through 
provision of scholarships to women and mahram (brother, husbands) both for allowing women to complete their training and studies in the digital technologies, which is an attempt for changing the status quo.

"The Ministry of Education offers to talented women and willing to study abroad scholarships for their husbands or brothers to accompany them during their study periods." [Manall $G]$

The academic group reported the similar strategy for allowing female staff to complete studies and training in foreign universities as part of staff development programs.

"We provide generous scholarships to female staff to support their studies and male member of their families who do not want to send their daughters alone to the foreign universities." [ $\mathrm{Ahmad} / A]$

These data indicated that both government and academic institutions encouraging and supporting Saudi women aspiring to pursue careers in digital technologies. Many participants from government group. However, these data do not reflect on the status quo of those women who have male members of their families unwilling to travel due to some other family responsibilities. This means that they can not avail of developing skills and competencies in digital technologies.

According to Hamdan (2005), very Saudi citizen has a right to education from primary level to college. Over time, the number of women graduates has increased in public universities in different fields, while today about fifty-eight per cent of all graduates are female.

These changing trends of participation in education are very important to my research because it is an established fact that higher learning leads to better employment and higher pay. Moreover, to compete in the new information economy, women will need an education and training in technology to access the jobs of the future.

Indeed, half of the interviewees believed education has changed dramatically, having been driven by programmes such as the King Abdullah Scholarship Programme. Batool/B, Sara/A, Lama/A, Mona/B and Shatha/B again expressed this view. For example, Batool/B said,

"The education system is in constant change...I heard about this from my cousin because I stopped studying due to a disagreement between my mom and dad. On the other hand, the scholarship system allows Saudi girls to learn about the outside world and other cultures by studying abroad."

The King Abdullah Foreign Scholarship Programme could be said to constitute the first significant transformation of the education system in Bachelor's, Master's and doctorate degrees. This programme represents a considerable evolution of the quality of education and learning obtained from other cultures, with the consequence Saudi youth will be able to improve their level of education for the benefit of both public and private sectors. 


\subsection{Vocational Training Opportunities for Women}

Many participants from the academic, business and government groups agreed to the availability of training opportunities for women in digital technologies to a certain extent. A participant agreed to the compatibility of curriculum of Computer Science with the labour market.

"Currently it is unified and developed. For example, the Computer Curriculum at vocational institutions now works in harmony with the labour market."

She as a Master's degree in curricula and teaching methods and is a computer teacher. She had helped her students to invent robots and participate in a competition in Austria. She was able to encourage her students in high school to enter the competition, which is an example of teacher leadership encouraging the skills required in the new economy.

Her opinion reflects the improvement in the teaching of technology subjects and suggests that education in KSA has the potential to develop future career opportunities in technology. Some progress in this area has been made, such as a contract between the government and the Microsoft Corporation to improve digital technology in the field of education. This is a positive start to considering a progressive role for the private or business sector, working with the Saudi state to foster a climate of greater gender equality within education.

In some cases, students could set up online joint-ventures and faculties could offer Massive Open Online Courses (MOOCs) that provide anywhere-anytime access to academic subjects. To preserve cultural gender segregation which is important in Saudi Arabia, electronic filters are also used to enable male-female interaction in which the male cannot see the female, although they can communicate either in speech or text.

Distance learning, tele-conference or group participation is now possible in real time, facilitating teacher-student interaction through face-to-face or remote connection. Some participants from the Academic group (four (4) respondents) felt that they were now successful in using this new communicational technology to provide a high level of assistance to develop their students, such as advanced technical workshops for graduates. As one of them attested:

"The Institute provides the students with the knowledge by making the curricula available on the website and technical workshops for [soft] skills development."

She indicated that there is development in the way of applying the technology in education process, including using websites and technical workshops, which can potentially make a difference to learning. One example is when the presenter explains his or her subject and the attendees have real-time communications through which all participants can exchange information instantly.

Another respondent was a very active teacher, going beyond conventional expectations in working with her students. She felt that Saudi education in general, needs high quality teaching skills: 
"Teaching skills is available. It was through the announcement of a competition between schools, in the programming of the robot. We trained the students more hours per week in a dedicated activity. Then we went to Austria to show the robot with the competing schools from China."

In computer science, for instance, it is not uncommon for robots to be used as a learning tool. Indeed, training in the field of robotics is a good starting point enabling Saudi girls to explore new knowledge and skills. Among other things, such skills have relevance to their careers, even if they should ultimately choose the dominant fields of female employment in education, nursing and health services.

She understood this advantage and worked hard alongside her students to participate in a competition between schools internationally. This example shows that practical training is now available and should improve the opportunities for other applications in the future. Hence, the interview with one of the respondents focus on teaching policy towards technology skill acquisition from the perspective of academia alongside other technology-related programmes available to women in universities and schools.

Indeed, there is currently a debate about the merits of a practical or theoretical education in digital technology. It is true that many people can secure well-paid jobs using their 'practical' computer skills without knowing any theory. Nonetheless, they may not progress very far without the understanding of the theory on which their skills are built.

Practical education means acquiring knowledge with practical experience, so enabling the student to learn how to do things in the real world. In a world of computers, this means being fully trained and competent in using software programs, apps, communications and the electronic devices on which they operate.

One respondent showed a deeper understanding and insight of technology education. In addition to academic skills, he mentioned that emotional/caring attributes and professional ethics awareness were also required and that these are included in the curricula. These attributes are relevant because of the high percentage of women employed in the medical field. Sultan/A said:

"Our curricula are based on solving problems. Everyone can read the medical analyses and radiology reports. Female students in our university are able to deal with the recent anaesthesia machines in the anaesthesia department and equipment of the intensive care unit (ICU) in addition to all equipment of heart, kidney and respirators. Also, they learn how to use technology to fill the health file or enter the health information through collecting information about the patient and doctor."

In the health sector, it seems that all students, both female and male, study the same curriculum. As a result, both sexes develop the ability to operate technical equipment used in specialist medical fields, such as in anaesthesia and intensive care units (ICU). In addition, the above comments refer to the giving the practical digital skills to medical students, but it does not mention that development of 
skills in the technologies in other disciplines such as education and information systems used by business organizations.

Sultan/A also referred and gave examples of the different types of tools that use technology. Women excel in these areas because of the continuing emphasis on this domain as a suitable career path for women. Moreover, women receive highly advanced training as part of their higher education.

Vocational education is available, through academic institutions, in subjects that prepare students for technology-related occupations. In some cases, the university may have special training labs and tools to teach students the practical skills and applications. Taking a more positive perspective, another two respondents confirmed that women receive special training in their work environment and that training is available in technological areas. As one of them attested,

"The private sector provides female workers with training to use technology in call centre jobs and cashiers. In our company, all female employees are professionally trained to use softwarel a program that allows them to communicate and hold meetings remotely."

There have been some improvements in education in the technology sector, but it was mostly theoretical in approach. Indeed, they agree with each other's comments but there is a lot yet to be done for improving the training experiences of students at the vocational institutions. She said:

"Vocational education is available through the Institute plan for four semesters... I think that effective polices at the institutional levels are required to improve the training experiences of students in order to be able to teach at the University using the educational technologies."

Technical competency is not limited to a university education. For many women, a vocational education/training programme is more useful. One good example here is the recent training of women to maintain and repair mobile devices. Technical competency goes to the heart of technological training as an outcome that is now pertinent to Saudi women and their career progression in the technology sector. One of them suggested that training is now widely available,

"Practical training is available in the Department of Pharmacology. Also, training is available in the applied sciences, such as laboratories, radiology, physical therapy, anaesthesia and heart technology."

The health sector is second only to the education sector in terms of women's employment in Saudi Arabia. Both these fields require vocational and professional training, while the Department of Pharmacology now offers practical technical training for women, an activity previously dominated by men. This change in policy improves access to equal skills training for women, thereby helping them to compete and achieve equal access and opportunity to employment and careers.

These data from participants showed that vocational training opportunities in digital technologies are available for Saudi women. Simply training women how 
to use technology or software is too restrictive, for if they had the opportunity to understand how the technology works, then they would be empowered to pursue multiple career choices. In addition, the Saudi government has put reform of the education system at the centre of its initiative to diversify the economy and prepare the workforce for the jobs of the future, known as Vision 2030. In starting to reform the curricula related to subjects of science and technologies and policy, the aim of the Ministry of the Education here is to harmonise them to improve computer science education and training in general. Moreover, Vision 2030 includes the objective of providing women with the opportunity to pursue careers in the technology-based occupations generated by the new economy.

\section{Discussion}

This paper discusses two major issues which were based the findings of this study; 1) The training opportunities through collaboration between academic institutions and businesses; 2) Vocational Education and Training Opportunities

It was found by this study that aura of cooperation between academic institutions and businesses exist in Saudi Arabia for training and up-skilling female students and women employees. The results showed that universities are willing to provide library services and allocation of slots on different courses dedicated for female employees in industries, while the stakeholders from different industries in this study showed prospects for accepting female students in the internships programs allowing them to complete their final year projects in digital technologies. These arrangements raise the potential of equipping women with digital skills and training, so that they can participate in the labour-market created by the digital technologies.

Though provision of library services were not reported by all participants from the academic group, however, the initiative itself represent the positive sense of cooperation and supports the symbiotic relationship between female academia and industry. If this approach is replicated in all female academic universities, then strength of association between the industry and universities will not only be strengthened for exchange of resources, but it also will pave the way for higher entry of women aspiring for digital careers in the digitalizing economy of Saudi Arabia. In addition, this should be noted that provision of library services was reported by a single female academia participating in this study, and therefore, I cannot extrapolate this finding to all other participants from academia group.

Many other studies have showed the similar findings. For example, European Union has adopted the approach of striking collaboration between academic institutions and industries in order to provide the most needed digital skills and training to female employees (European Commission, 2017). Smith (2006) expressed that training provided by businesses to women in digital technologies most likely impact positively on motivation and participation of women in the labour market. Digibyte (2018) affirmed that exchange of resources between the 
academic institutions and industry can decrease the gender gap at workplaces, and is an important step to enhance the participation rate of women in the digital transformation of economies and societies.

According to Bassanini et al. (2005), there is an intrinsic relationship exists between the academic institutions and the industry, which naturally drives the collaboration between these institutions within a given socio-cultural context. Both academia and industry are dependent on each other for satisfaction of their needs. For example, businesses are reliant on academic institutions for filling the knowledge gap of women employees through collaboration with academic institutions, while the academic institutions are in need of businesses for internships for female students, so that they can gain the hands-on experience in the industrial environment (Ellinger, 2002). These measures are more likely to increase the employment prospects for women.

The issues relating to socio-cultural norms can affect the extent of collaboration between the educational institutions and the industry. The corporate world is male dominated, while the academic staff in female universities encounter difficulties in meeting men for signing collaborative initiatives with male dominated industries, This issue was highlighted by Tartari and Salter (2015) in the UK universities where female academic staff were found be less oriented towards making collaborative arrangements with industry compared to male counterparts in the universities.

The findings reported the training opportunities at two levels: educational level in form training events organized by academic institutions for female students in order to train them for competing for employment opportunities resulting from the deployment of digital technologies in Saudi Arabia. It was found that academic institutions have in place good arrangements for providing training in vocational fields such as applied science, pharmacology, public health sector and IT. Interesting patterns were observed in relation to training arrangements.

The academic institutions were found to provide the vocational training to women employees from business, and women students aspiring to build careers in digital technologies without any affiliation to any business organization. Therefore, vocational education and training institutions appear to serve as bridge between the potential employees and the business world.

Several studies have acknowledged the role of vocational educational and training institutions in provision of employability skills to women with aim to reduce gender gap in the international labour market (Rainbird, 2009; Cooke, 2005; Bosch \& Charest, 2009). Hence, it can be argued that with availability of vocational education and training opportunities in Saudi Arabia, Saudi women stand a better chance to gain employability skills required by employers in the labour market created by digital technologies in Saudi Arabia.

It was discovered that Computer Science curricula are designed by academic institutions in line with the labour market. This theme was not found for other 
subject areas mentioned by participants such as medical and applied sciences. This shows that curricula of applied science and medical and health related education might not have updated in accordance with other subjects. As this was not the main research question to be addressed by this study, therefore, future research work needs to be planned to discover whether the training related programs and curricula follow the trends of labour market's needs. It is very critical to organise the vocational education and training for Saudi women in accordance with market needs which can determined through surveys of local and international employers' employability skills (Bosch \& Charest, 2009).

Participants seem to agree to the fact that compatibility between vocational curricula and labour market needs is required for allowing women to pursue careers in digital careers. Bosch and Charest (2009) viewed that academic institutions can show productivity and contribute to national economy through providing training and education to students in line with the market needs. Another study reinforced compatibility between vocational curricula and labour market, which support the conclusion reached by my study (Van de Werfhorst, 2004).

Özkanli (2007) found that working women in the Turkish universities were entrenched into their jobs due to attending vocational courses, thereby increasing chances for women to go up the ladder of progression and promotions. The vocational training provided by academic institutions in Saudi Arabia for women in areas of teaching, workshops in digital technologies might increase the similar employment and promotion opportunities for women. Murgor et al. (2013) reported the technical and vocational training acquired by female in Kenya, and came to conclusion that vocational and training opportunities are available for women, but they are given the skills to apply numerical skills, critical analysis and interpersonal skills, though they provided with IT skills. This situation led to a lower participation of women in the labour market. Hence, this underscores the focus of employability skills while organizing the vocational education and training systems in Saudi Arabia.

Interesting it was revealed by data some vocational training institutions send women to foreign universities to obtain vocational training. My personal observations also affirm this finding that several academic institutions are following lead of sending their women employees aboard to learn as to how to apply the digital technologies in various business contexts such as robotic technologies which were mentioned by participants in this study. Rainbird (2009) argued that UK-based vocational and training educational system enhances the learning experience of students, and aims to equip women students with essential skills valued by employers.

Some studies in Chine indicated that vocational education and training systems in Chinese and Australian academic institutions provide the vocational training and employability skills matching with regional national and global workplace settings (Potter et al., 2011; Cooke, 2005; Bosch \& Charest, 2009). These data indicate that Saudi women given the opportunity to study in the internally 
recognized vocational education and training systems, have higher probability of participation in employment opportunities resulting from digitalization of Saudi economy and society.

Does the availability of technical and vocational opportunities for women ensure the increased participation of Saudi women in the labour market? There are two types of skills: non-digital skills (e.g. critical thinking, team work, interpersonal skill, communication) and digital skills. If the technical and vocational training opportunities for women enhances the digital skills, and are unable to foster non-digital skills, the participation of women in Saudi labour market can be compromised (World Bank, 2007; Foster, 2012).

There are some studies which showed that if women are not provided key skills in areas of communication, team work, interpersonal skills and critical analysis skills despite the provision of IT skills, it causes to reduce participation of women (Murgor, 2013; Kazilan et al., 2009). Some other studies have reported the soft skills and digital competencies both are needed to reduce gender gap in the labour market (World Bank, 2006; Rahim \& Hanafi, 2007). These data indicate the importance of some non-digital skills for participation of women in the labour market.

This is one of limitations of the data presented in this study, that it does not reveal different types of vocational and technical skills from training opportunities given to the women aspiring to pursue digital careers in Saudi Arabia. Hence, future study is required to investigate into the types of employability skills offered to Saudi women in vocational training institutions in Saudi Arabia. This will help find out the participation rate of women based on employability skills rather than building conclusions in relation to women's participation in Saudi labour market based on only availability of vocational training for women.

\section{Conclusion}

Though this study found that vocational education and training opportunities are available for Saudi women aspiring to follow careers in digital technologies, but utilization of such opportunities may be compromised if women were not motivated to take up vocational training courses for improving their employment prospects in digital technologies. Participation rate of women to take up the vocational education and training opportunities should be increased through incentive program by Saudi government for women and arrangement of employers arranged workshops aiming to raise the awareness among women about the need of vocational education and training in digital technologies.

The country socio-cultural norms include the segregation of men and women in educational and workplace environment. These norms should be respected. Most of the change initiatives fail because they try to change the basic ideologies of the workers or stakeholders involved in the changed. Therefore, any change radicalizing social settings such as creating mixed workplaces or mixed training and skills development centres for women should be avoided in order to increase 
the willingness of the guardians of women (father, brothers, and husband) to allow women to participate in the skill development programs mentioned by participants in this study. The best example reported in the data reported in my study included training centres at female campus of King Saud University. Such arrangements should be relocated at every female campus for motivating Saudi women to join their local skills centres without travelling to far-off women's skills development centres.

\section{Conflicts of Interest}

The author declares no conflicts of interest regarding the publication of this paper.

\section{References}

Alharbi, A. S. (2019, March). Assessment of Organizational Digital Transformation in Saudi Arabia. In 2019 6th International Conference on Computing for Sustainable Global Development (INDIACom) (pp. 1292-1297). Institute of Electrical and Electronics Engineers.

Al-Helayyil, A., Claps, M., Rajan, R., \& Schaller, O. (2016). Saudi Arabia Vision 2030: Envisioning a Technology-Led Transformation-IDC's Initial View. IDC\# CEMA41301016. International Data Corporation.

Amuda, Y. J. (2020). Potential Entrepreneurship Careers of Fourth Industrial RevolutionBased in Saudi Arabia. Academy of Entrepreneurship Journal, 26, 1-8.

Bandura, A. (2002). Growing Primacy of Human Agency in Adaptation and Change in the Electronic Era. European Psychologist, 7, 2-26.

https://doi.org/10.1027//1016-9040.7.1.2

Barua, A., \& Barua, A. (2012). Gendering the Digital Body: Women and Computers. AI \& SOCIETY, 27, 465-477. https://doi.org/10.1007/s00146-012-0371-9

Bassanini, A., Booth, A. L., Brunello, G., De Paola, M., \& Leuven, E. (2005). Workplace training in Europe. International Zeolite Association.

Bauer, M. W., \& Gaskell, G. (2000). Qualitative Researching with Text, Image and Sound: A Practical Handbook for Social Research. Sage. https://doi.org/10.4135/9781849209731

Bosch, G., \& Charest, J. (Eds.). (2009). Vocational Training: International Perspectives. Routledge. https://doi.org/10.4324/9780203869574

Braun, V., \& Clarke, V. (2006). Using Thematic Analysis in Psychology. Qualitative Research Inpsychology, 3, 77-101. https://doi.org/10.1191/1478088706qp063oa

Broadband Commission (2017). Working Group on the Digital Gender Divide Recommendations for Action: Bridging the Gender Gap in Internet and Broadband Access and Use. Broadband Commission

https://www.broadbandcommission.org/working-groups/digital-gender-divide-2017/

Clarke, R., Wright, P., \& McCarthy, J. (2012). Sharing Narrative and Experience: Digital Stories and Portraits at a Women's Centre. In CHP 12 Extended Abstracts on Human Factors in Computing Systems (pp. 1505-1510). Association for Computing Machinery. https://doi.org/10.1145/2212776.2223663

Collins, J., \& Hussey, R. (2003). Business Research. A Practical Guide for Undergraduate and Postgraduate Students. Polgrave Macmillan. 
Cooke, F. (2005). Vocational and Enterprise Training in China: Policy, Practice and Prospect. Journal of the Asia Pacific Economy, 10, 26-55.

https://doi.org/10.1080/1354786042000309062

Digibyte (2018). More Women in Digital Sector: A Key to Europe's Successful Digital future: International Women's Day 2018.

https://digital-strategy.ec.europa.eu/en/news/eu-countries-commit-boost-participation -women-digital

Economic and Social Council of United Nations (2018). Building Digital Competencies to Benefit from Existing and Emerging Technologies with Special Focus on Gender and Youth Dimensions. United Nations.

Ellinger, A. D. (2002). Mentoring in Contexts: The Workplace and Educational Institutions. In C. A. Hansman (Ed.), Critical Perspectives on Mentoring: Trends and Issues (pp. 15-26). Education Resources Information Center.

Eshet-Alkalai, Y. (2004). Digital Literacy: A Conceptual Framework for Survival Skills in the Digital Era. Journal of Educational Multimedia and Hypermedia, 13, 93-106.

European Commission (2017). ICT for Work, Digital Skills in the Workplace. https://digital-skills-jobs.europa.eu/en/inspiration/research/ict-work-digital-skills-wor kplace-2017

Ferrari, A. (2013). DIGCOMP: A Framework for Developing and Understanding Digital Competence in Europe. European Union.

Foster, H. (2012). Women and TVET. Report of the UNESCO-UNEVOC, UNESCOUNEVOC International Centre for Technical and Vocational Education and Training UN Campus.

Göransson, B., \& Rolfstam, M. (2013). Development and Use of Gender-Specific Technologies: Evidence from China, Poland and Sweden. Gender, Technology and Development, 17, 281-312. https://doi.org/10.1177/0971852413498740

Gupta, N. (2015). Rethinking the Relationship between Gender and Technology: A Study of the Indian Example. Work, Employment and Society, 29, 661-672.

https://doi.org/10.1177/0950017014556410

Gurung, L. (2018). The Digital Divide: An Inquiry from Feminist Perspectives. Dhaulagiri Journal of Sociology and Anthropology, 12, 50-57.

https://doi.org/10.3126/dsaj.v12i0.22179

Hamdan, A. (2005). Women and Education in Saudi Arabia: Challenges and Achievements. International Education Journal, 6, 42-64.

Herbert, S. (2017). Digital Development and the Digital Gender Gap (pp. 2-11). Knowledge, Evidence and Learning for Development.

https://assets.publishing.service.gov.uk/media/5a5f228f40f0b652634c6f4a/249-Digital-d evelopment-and-the-digital-gender-gap.pdf

Husse, J., \& Hussey, R. (1997). Business Research: A Practical Guide for Undergraduate and Postgraduate Students. Macmillan Business.

Kane, G. C., Palmer, D., Phillips, A. N., Kiron, D., \& Buckley, N. (2015). Strategy, Not Technology, Drives Digital Transformation. MIT Sloan Management Review and Deloitte University Press, 1-25.

Kazilan, F., Hamzah, R., \& Bakar, A. R. (2009). Employability Skills among the Students of Technical and Vocational Training Centers in Malaysia. European Journal of Social Sciences, 9, 147-160.

Leach, L., \& Turner, S. (2015). Computers Users Do Gender: The Co-Production of Gen- 
der and Communications Technology. Sage Open, 5, 1-14. https://doi.org/10.1177/2158244015604693

Melhem, S., Morell, C., \& Tandon, N. (2009). Information and Communication Technologies for Women's Socio-Economic Empowerment. The World Bank. https://doi.org/10.1596/978-0-8213-8133-5

Murgor, T. K. (2013). Relationship between Technical and Vocational Acquired Skills and Skills Required in Job Market; Evidence from TVET Institutions, Uasin Gishu County, Kenya. Journal of Education and Practice, 4, 77-83.

Neuman, L. W. (2002). Social Research Methods: Qualitative and Quantitative Approaches. Allyn and Bacon.

OECD (Organisation for Economic Co-Operation and Development) (2016). Skills for a Digital World, Policy Brief on the Future of Work. In World Economic Forum, 2016, The Future of Jobs: Employment, Skills and Workforce Strategy for the Fourth Industrial Revolution. Organisation for Economic Co-Operation and Development

Özkanli, Ö. (2007). The Situation of Academic Women in Turkey. Egitim ve Bilim, 32, 59-70.

Pande, R., \& Weide, T. V. (2012). Globalization, Technology, Diffusion and Gender Disparity: Social Impacts of ICTs. IGI Global. https://doi.org/10.4018/978-1-4666-0020-1

Perry, C. (2000). Case Research in Marketing. The Marketing Review, 1, 303-323. https://doi.org/10.1362/1469347002530790

Potter, P., Lai, R. Z., Maturu, N., Stamberger, E., Stephens, N., \& Sze, P. (2011). Vocational Education and Training in China.

https://www.oecd.org/education/skills-beyond-school/45494135.pdf

Rahim, A., \& Hanafi, I. (2007). Assessing Employability Skills of Technical-Vocational Students in Malaysia. Journal of Social Sciences, 3, 202-207

Rainbird, H. (2009). Vocational Education and Training in the United Kingdom. In G. Bosch, \& J. Charest (Eds.), Vocational Training (pp. 258-286). Routledge.

Rashid, A. T. (2016). Digital Inclusion and Social Inequality: Gender Differences in ICT Access and Use in Five Developing Countries. Gender, Technology and Development, 20, 306-332. https://doi.org/10.1177/0971852416660651

Reddy, S., \& Minoiu, C. (2009). Real Income Stagnation of Countries 1960-2001. The Journal of Development Studies, 45, 1-23. https://doi.org/10.1080/00220380802265249

Rosenthal, R. L. (2008). Older Computer-Literate Women: Their Motivations, Obstacles, and Paths to Success. Educational Gerontology, 34, 610-626.

https://doi.org/10.1080/03601270801949427

Sabbagh, K., Friedrich, R., El-Darwiche, B., Singh, M., Ganediwalla, S. A. N. D. E. E. P., \& Katz, R. A. U. L. (2012). Maximizing the Impact of Digitization. In S. Dutta, \& B. Bilbao-Osorio (Eds.), The Global Information Technology Report (pp. 121-133). World Economic Forum.

Saunders, M. N. (2012). Choosing Research Participants. In G. Symon, \& C. Cassell (Eds.), Qualitative Organizational Research: Coremethods and Current Challenges (35-52). SAGE Publications, Inc. https://doi.org/10.4135/9781526435620.n3

Smith, E. (2006). A Woman's Work Is Never Certificated? How the Implementation of Nationally Recognised Training in Workplaces Helps Women Get Qualifications. Journal of Vocational Education and Training, 58, 531-549.

https://doi.org/10.1080/13636820601007616

Smith, J. A. (2007). Qualitative Psychology: A Practical Guide to Research Methods. Sage. 
Statista (2018). Population Number in Saudi Arabia in the Middle of 2018, by Gender and Nationality.

https://www.statista.com/statistics/616737/saudi-arabia-population-by-gender-and-nat ional-

ity/\#: :text=The\%20largest\%20population\%20group\%20in,foreigners $\% 20$ dwelling\%20i n\%20Saudi\%20Arabia

Tartari, V., \& Salter, A. (2015). The Engagement Gap: Exploring Gender Differences in University-Industry Collaboration Activities. Research Policy, 44, 1176-1191.

https://doi.org/10.1016/j.respol.2015.01.014

Van de Werfhorst, H. G. (2004). Systems of Educational Specialization and Labor Market Outcomes in Norway, Australia, and the Netherlands. International Journal of Comparative Sociology, 45, 315-335. https://doi.org/10.1177/0020715204054154

Vaganova, O. I., Smirnova, Z. V., Gruzdeva, M. L., Chaykina, Z. V., \& Ilyashenko, L. I. (2019). Development of Training Content for Master Students in Course "Mechatronics and Robotics" at the University. Amazonia Investiga, 8, 694-700.

Van Dijk, J. A. G. M., \& Van Deursen, A. J. A. M. (2014). Digital Skills: Unlocking the Information Society. Palgrave Macmillan. https://doi.org/10.1057/9781137437037

Woishi, W. (2019). The Impact of Digitalization on the Economy of KSA in the Context of Vision 2030. Internatioanl Journal of Engineering Applied Sciences and Technology, 4, 312-316. https://doi.org/10.33564/IJEAST.2019.v04i04.051

World Bank (2006). World Development Report 2007: Development and the Next Generation. The World Bank.

World Bank (2007). World Development Report 2008. World Bank.

World Economic Forum (2016). The Future of Jobs; Employment, Skills and Workforce Strategy for the Fourth Industrial Revolution.

Youssef, A. B., Boubaker, S., Dedaj, B., \& Carabregu-Vokshi, M. (2020). Digitalization of the Economy and Entrepreneurship Intention. Technological Forecasting and Social Change, 164, Article ID: 120043. https://doi.org/10.1016/j.techfore.2020.120043 